\title{
Brain Diabetes: The New Type 3 Diabetes
}

\section{Carla Mannu* and Marco Songini}

Diabetology Unit, (A.S.R.I.S) Onlus Association for the Study and Research of Diabetes, San Michele Hospital, Sardinia, Cagliari, Italy

*Corresponding author: Mannu C, Research Fellow, Diabetology Unit, (A.S.R.I.S) Onlus Association for the Study and Research of Diabetes in Sardinia, San Michele Hospital, Sardinia, Cagliari, Italy, Tel: +39-328665508; E-mail: carla.mannu@gmail.com

Rec Date: June 18, 2018, Acc Date: June 22, 2018, Pub Date: June 25, 2018

Copyright: (02018 Mannu C, et al. This is an open-access article distributed under the terms of the Creative Commons Attribution License, which permits unrestricted use, distribution, and reproduction in any medium, provided the original author and source are credited.

\section{Editorial}

Diabetes is a metabolic disorder characterized by increased blood glucose (hyperglycemia) due to total or partial deficiency of insulin (a hormone produced by the pancreas) or its malfunction. Classification and diagnosis of diabetes (once type 1 and type 2 only) has been changing over time, it's time now to retune all criteria [1,2]. A correct diagnosis of diabetes (type and subtype) is important in order to set the best treatment to patients, to carry on a screening of complications and associated conditions for further genetic counseling of the families [3].

Diabetes is especially fearsome for long-term chronic complications due to damage and dysfunction of various organs: heart, arteries, kidneys, eyes and nervous system. In regards to the complications of the central nervous system (CNS), many studies have now showed a relationship between both type 1 and type 2 diabetes and brain dysfunction and dementia.

In type 2 diabetes, insulin levels in the brain can be decreased or increased, along with insulin receptor desensitization [4]. It was also observed that patients with diabetes, who develop dementia, have a unique form of the disease, although similar to vascular dementia. Glucose and insulin are therefore identified as important moderators of cognitive function [5]. Long before antipsychotic drugs became standard therapy, studies showed abnormal glucose tolerance in patients with early dementia [6,7]. Repeated hyper- and/or hypoglycemia or basal blood glucose values barely over the norm (IFG, impaired fasting glucose), not yet up to the diagnostic values for diabetes, have been linked to cognitive deficits and altered brain anatomy and connectivity. In diabetic patients, however, a clear correlation of glycemia with the memory deficit has been shown $[8,9]$.

Is Alzheimer's a new form of diabetes? Currently, scientists report new findings linking insulin to the cognitive disorder of the brain, the correlation so strong that some researchers are calling Alzheimer's disease the new Type 3 Diabetes [10].

Could Alzheimer's disease and dementia be linked to what we eat?

A study was carried out on the comparison between the feeding of an African American population of Indianapolis (USA, population originating in Nigeria) and a population of Africans from Ibadan (Nigeria). The populations had the same genetic background. The American population followed a habitual mixed diet especially rich in sugar and saturated fats (junk food). The African population instead followed a local poor diet based on vegetables, fruits, palm oil, and fish. After 5 years of follow-up, there was a progressive mental deterioration of $3.25 \%$ in the African-American population compared to $1.35 \%$ in the Nigerian population [11].
Could we prevent the chronic complications of diabetes with a proper nutrition (AGE)? At the same time, could it be effective to prevent brain diabetes as well?

Could diabetes drugs help people without overt diabetes to reduce the risk of Alzheimer's disease and/or dementia? This is primary prevention.

Can these drugs be used in people with diabetes/IFG and with a family risk of dementia or Alzheimer's or other CNS disorders? This is secondary prevention.

Some symptoms of 'senile' dementia may be defeated by an insulin spray administered intranasally. New oral therapies, a combination of anti-diabetic drugs such as liraglutide and glitazones, are now being tested in dementia and Alzheimer's disease [12,13].

Finally, Alzheimer's disease and diabetes are joined at epidemiological, genetic and molecular levels. Both diseases would start years before the beginning of their clinical symptoms. The chronic insulin resistance appears to significant affect cognition and increase the risk of dementia. Insulin has important, recently recognized, effects on the brain. It has indeed played either a beneficial or protective role towards cognitive function. These chronic conditions are susceptible to 'targeted' intervention with 'anti-diabetic' drugs as well as good control of the glycemia with an appropriate lifestyle. Intranasal insulin and/or incretins may represent an important therapeutic tool for preventing or treating cognitive decline. In conclusion, further studies are needed to confirm the results found and help the effective prevention of brain diabetes.

\section{References}

1. Schwartz SS, Epstein S, Corkey BE, Grant SF, Gavin JR 3rd, et al. (2016) The time is right for a new classification system for diabetes: Rationale and implications of the $\beta$-cell-centric classification schema. Diabetes Care 39: 179-186.

2. American Diabetes Association (2017) Classification and diagnosis of diabetes. Diabetes Care 40: S11-S24.

3. Pacaud MD (2016) A description of clinician reported diagnosis of type 2 diabetes and other non-type 1 diabetes included in a large international multicentered Pediatric Diabetes Registry (SWEET). Pediatric Diabetes. S23: 24-31.

4. Cholerton B, Baker LD, Craft S (2013) Insulin, cognition, and dementia. Eur J Pharmacol 719: 170-179.

5. Morley P (2017) Diabetes: The diabetic brain. Nat Rev Endocrinol 13: 570-571.

6. Rajkumar K, Horsdal HT, Wimberley T, Cohen D, Mors O, et al. (2017) Endogenous and antipsychotic-related risks for diabetes mellitus in young people with schizophrenia: A Danish population-based cohort study. Am J Psychiatry 174: 686-694.

7. Andreassen OA (2017) Diabetes and schizophrenia-new findings for an old puzzle. Am J Psychiatry 174: 616-617. 
8. Saggar M, Tsalikian E, Mauras N, Mazaika P, White NH, et al. (2017) Diabetes Research in Children Network (DirecNet). Compensatory hyperconnectivity in developing brains of young children with type 1 diabetes. Diabetes 66: 754-762.

9. Crane PK, Walker R, Hubbard RA, Li G, Nathan DM, et al. (2013) Glucose levels and risk of dementia. N Engl J Med 369: 540-548.

10. Skinner JS, Morgan A, Hernandez-Saucedo H, Hansen A, Corbett S, et al. (2015) Associations between Markers of Glucose and Insulin function and cognitive function in healthy African American elders. J Gerontol Geriatr Res 4: 232.

11. Hendrie HC, Ogunniyi A, Hall KS, Baiyewu O, Unverzagt FW, et al. (2001) Incidence of dementia and Alzheimer disease in 2 communities:
Yoruba residing in Ibadan, Nigeria, and African Americans residing in Indianapolis, Indiana. JAMA. 285: 739-747.

12. Salameh TS, Bullock KM, Hujoel IA, Niehoff ML, Wolden-Hanson T, et al. (2015) Central nervous system delivery of intranasal insulin: Mechanisms of uptake and effects on cognition. J Alzheimers Dis 47: 715-728.

13. Cao B, Rosenblat JD, Brietzke E, Park C, Lee Y, et al. (2018) Comparative efficacy and acceptability of anti-diabetic agents for Alzheimer's disease and mild cognitive impairment: A systematic review and network metaanalysis. Diabetes Obes Metab 20: 1040-1043. 